\title{
Socialização e política
}

\author{
Jackson A lves de Aquino*
}

\begin{abstract}
R esumo: O artigo, após uma breve caracterização das sociedades democráticas, apresenta uma revisão de literatura sobre desenvolvimento moral e sobre socialização, relacionando os dois temas. A seguir, é disautidb o impacto de diferentes aulturas para a democracia. Finalmente, são feitas considerações sobre a importância do processo de socialização para a ordem democrática.
\end{abstract}

Palavr as-chave: democracia, participação política, socialização, desenvolvimento moral.

0 objetivo deste artigo é fazer alguns comentários sobre a importância do desenvolvimento moral do indivíduo e do processo de socialização pelo qual ele passou para seu comportamento como cidadão adulto. Trata-se de uma breve revisão da bibliografia existente sobre o tema e não da apresentação dos resultados de uma pesquisa empírica própria. ${ }^{1}$

Este trabalho contém quatro seções. A primeira procura fornecer uma caracterização das sociedades democráticas. A segunda apresenta uma revisão da literatura sobre social ização e desenvolvimento moral e, na terceira, é discutido o impacto de diferentes características culturais sobre a democracia. Por fim, são feitas algumas últimas considerações sobre o tema.

\footnotetext{
* M estre em Sociologia pela Universidade Federal do Ceará e doutorando em Sociologia e Política pela Universidade Federal de M inas Gerais.

1. U ma extensa lista com bibliografia sobre socialização e política, organizada por Virginia Sapiro, pode ser encontrada na Internet (http://polisci.wisc.edu/users/sapiro/ ps477_935/socz_bib.htm). Este artigo foi originalmente desenvolvido para o curso Debates Contemporâneos em Teoria Democrática, ministrado pelo professor Leonardo Avritzer (UFMG). As discussões em sala de aula e a bibliografia do curso foram importantes, em especial, para a elaboração da primeira seção do artigo.
}

Características de uma sociedade democrática

Para R ousseau, por vezes conhecido como o teórico da democracia direta, a democracia mais próxima do ideal de participação plena e igualitária estaria disponível apenas para comunidades muito pequenas e homogêneas. 0 homem teria uma natureza incompatível com esse ideal democrático. Isso está claramente expresso numa de suas famosas afirmações: "Se existisse um povo de deuses, governar-se-ia democraticamente. Governo tão perfeito não convém aos homens" (Rousseau, 1987, p. 151). Rousseau defendia como melhor forma de governo o que ele chamava de aristocracia eletiva:

Há [...] três espécies de aristocracia: natural, el etiva e hereditária. A primeira só convém a povos simples; a terceira é o pior de todos os governos. A segunda, o melhor Governo, é a aristocracia propriamente dita, estabelecida por eleição, meio pelo qual a probidade, as luzes e a experiência e todos os outros motivos de preferência e de estima pública constituem outras novas garantias de que se será governado sabiamente. (R ousseau, 1762, p. 154) 
A preocupação de Rousseau era menos com a formação do governo do que com a forma como eram elaboradas as leis, que para ele deveriam ser representativas do que denominava vontade geral, ou seja, a vontade de atender aos interesses de todos os membros da sociedade tomada como um todo e não aos interesses deste ou daquele indivíduo isoladamente. Rousseau acreditava que a vontade geral realizava-se na vontade da maioria.

$M$ enos confiante nos benefícios do voto da maioria era Schumpeter, para quem a democracia contemporânea não é muito mais do que a "concorrêncialivre pelo voto livre" (Schumpeter, 1961, p. 329). L onge do ideal do povo governando a si mesmo, Schumpeter via a democracia como o sistema em que uma elite governa, limitando-se a grande maioria da população apenas a votar em um ou outro dos candidatos da elite. E mesmo 0 ato de votar era visto por Schumpeter com um significado reduzido porque, para ele, o eleitor, em geral, não se interessa muito por política e vota com base em um conhecimento precário da realidade política e fazendo pouco uso de sua capacidade cognitiva. A expressão aristocracia eletiva seria mais adequada para rotular a definição de democracia de Schumpeter do que a do próprio Rousseau. Este pelo menos tinha uma maior confiança na produção das leis por um corpo legislativo. Para Schumpeter, legislação e administração eram produzidas "apenas como subprodutos da luta pelos cargos políticos" (Schumpeter, 1961, p. 348).

$\mathrm{K}$ elsen apresenta uma posição mais equilibrada do que Rousseau e Schumpeter. Ele não tem a visão simplista de que a decisão tomada por uma maioria represente a vontade geral, mas também não encara a produção de legislação e de governo apenas como subproduto de uma competição pelo voto. K elsen via as decisões tomadas pela maioria como resultantes dos compromissos mútuos assumidos pelos diversos e heterogêneos segmentos de uma população. A população de qual quer sociedade contemporânea é demasiadamente complexa para pensar em uma vontade geral única. 0 melhor que se pode imaginar é a obtenção de uma série de compromissos, na qual cada segmento cede um pouco para não perder tudo. A democracia seria o regime político que melhor permitiria se aproximar da produção desse compromisso entre os diversos segmentos de uma sociedade. Dada a heterogeneidade da população de uma sociedade moderna, é de se esperar a existência de uma multiplicidade de vontades particulares potencialmente conflitantes e, por conseguinte, de que nenhum segmento isoladamente seja mai oria. 0 processo de formação da mai oria seria, segundo K elsen, o que levaria a alcançar uma solução de compromisso para as divergências entre as vontades particulares. Pela regra da maioria, vários grupos teriam de negociar, fazer propostas e contrapropostas, até alcançarem unidade suficiente para vencer a minoria pelo voto. $M$ as esse processo não é equival ente a uma ditadura da maioria sobre a minoria porque, em primeiro lugar, a própria aceitação da regra da maioria implica o reconhecimento do direito à existência da minoria. Em segundo lugar, para formar a maioria, todos aqueles que se encontram compondo a maioria foram obrigados a fazer múltiplas concessões e, uma vez que a sociedade é heterogênea, parte dessas concessões deverá contemplar muitos dos interesses dos que se encontram na minoria. Para K elsen, a essência da democracia é o compromisso:

[...] todo o procedimento parlamentar, com sua técnica dialético-contraditória, baseada em discursos e réplicas, em argumentos e contraargumentos, tende a chegar a um compromisso. Este é o verdadei ro significado do princípio da maioria na democracia real. [...] Todo o procedimento parlamentar tende a criar um meiotermo entre os interesses opostos, uma resultante das forças sociais de sentido contrário. (K elsen, 1993, p. 70)

A o longo das últimas décadas, a teoria democrática tem passado de um conceito decisionista de deliberação para um conceito argumentativo de deliberação (A vritzer, 2000, p. 27). Poucas pessoas defendem ou já defenderam a existência de uma sociedade na qual todos os indivíduos tenham uma participação plena e igual itária nos assuntos políticos. Certamente muitos, senão todos os teóricos, considerariam isso desejável, sefosse possível. A utores clássicos, como Rousseau, Kelsen e Schumpeter, estavam prioritariamente preocupados 
com a forma como se constituem o governo e 0 parlamento. A utores contemporâneos também enfatizam a partici pação dos cidadãos em outras esferas da vida social que não são tipicamente reconhecidas como políticas, mas que também têm relevância para a vida política.

Putnam (1996), por exemplo, encontrou uma correlação de 0,92 entre desempenho institucional eum conjunto de fatores que ele utilizou para operacionalizar o conceito de civismo. Essa correlação implica que $85 \%$ da variação no desempenho institucional poderia ser explicada pelo nível de civismo da comunidade e este é um valor significativamente mais alto do que 0 normal mente encontrado nas correlações entre variáveis apresentadas em pesquisas sociais. Putnam mediu o desempenho institucional com base em um índice composto de um conjunto de medidas da qualidade do funcionamento da burocracia estatal (1996, p. 88). Q uanto à comunidade cívica, teoricamente seria aquela em que os cidadãos vêem-se como essencialmente iguais uns aos outros, interessam-se pelos problemas da comunidade e estão dispostos a contribuir para sua solução, confiando que os demais cidadãos compartilham dos mesmos sentimentos e também façam sua parte para resolver os problemas (Putnam, 1996, p. 100105). N a prática, o conceito foi operacionalizado considerando mais cívicas as regiões da Itália com maior participação dos cidadãos em associações, com maior taxa de comparecimento aos referendos, que se caracterizavam por maior leitura de jornais e onde menos se optava pelo voto preferencial, visto como um indicador de clientelismo e, portanto, de relações políticas verticais (1996, p. 105-109). Como se pode ver, Putnam não utilizou para caracterizar o civismo indicadores mais diretamente relacionados com a política institucional, como filiação a sindicatos e a partidos políticos, colaboração para campanhas eleitorais, participação em campanhas de boca-de-urna etc. Em todo caso, o cidadão ativo e participativo encontrado por Putnam e seus colaboradores nas comunidades cívicas é um indivíduo com características pessoais bem diferentes daquele descrito por Schumpeter como 0 apático eleitor típico.

0 achado empírico de Putnam e seus colaboradores corrobora a visão de que uma comu- nidade caracterizada por relações horizontais entre os cidadãos e por um elevado nível de participação deles na vida política não apenas se aproxima mais do ideal democrático, como também produz um governo mais eficaz na tarefa de proporcionar bem-estar para a população do que uma comunidade na qual predominem relações verticais.

A Iguns teóricos contemporâneos vêem a existência de associações como al go importante para uma democracia contar com uma participação mai or dos cidadãos nas decisões governamentais. U ma crítica comum a arranjos institucionais que permitem que as decisões governamentais sejam tomadas em conjunto com segmentos da sociedade civil pode ser traduzida como receio de tais práticas degenerarem em corporativismo e clientelismo. I sso não ocorrendo, entretanto, tem-se uma participação dos cidadãos nos negócios públicos que, além de legítima, é maior do que a possibilitada pela eleição periódica de governantes el egisladores. A antiga visão que igualava insulamento burocrático com eficiência está sendo substituída por uma visão de que a burocracia isolada pode, não obstante a competência profissional e a boa vontade de seus integrantes, resultar em ações ineficientes. Como argumenta Avritzer, está mudando a visão sobre quem detém o conhecimento necessário para gerir os negócios públicos:

Os novos arranjos deliberativos se baseiam em duas mudanças em relação a essa concepção de informação. A primeira éque o Estado, assim como o mercado, possui informações incompletas para a tomada de decisões e que, portanto, é preciso que os atores sociais tragam informações para que a deliberação contemple plenamente os problemas políticos envolvidos. Em segundo lugar, tais informações têm que ser partilhadas e discutidas, isso é, os arranjos deliberativos presumem que as informações ou soluções mais adequadas não são a priori detidas por nenhum dos atores e necessitam serem construídas coletivamente. (Avritzer, 2000, p. 44)

Cohen e Rogers (1995) propõem que as associações poderiam trabalhar em conjunto com as instituições governamentais "(1) na 
formulação de políticas públicas, (2) na coordenação da atividade econômica dentre dos limites da lei, e (3) na fiscalização e administração das políticas" (1995, p. 55). Os autores deixam claro, entretanto, que não é qualquer relação entre Estado e sociedade civil que pode ser considerada democracia deliberativa. 0 indivíduo tem de participar predisposto a ouvir as razões do outro e a se deixar convencer pela boa argumentação:

Entendemos por política deliberativa um processo de debate público cujo procedimento tem como referência considerações acerca do bem público e que dá forma às preferências dos participantes ao requerer que justifiquem suas opiniões. (Cohen e Rogers, 1995, p. 22)

Os cidadãos de uma democracia deliberativa têm de buscar o bem comum, ou seja, têm de estar dispostos a se engajar numa discussão aberta, o que, como veremos, é mais fácil para aqueles com uma moral bem desenvolvida e mais difícil para os que têm personalidade autoritária. A existência de associações éimportante para uma democracia deliberativa e, portanto, os indivíduos dessa sociedade devem ter facilidade de se envolver em relações horizontais e trabalhar voluntariamente em equipe. U m possível problema que pode ocorrer com uma democracia deliberativa baseada em associações seria a oligarquização das associações. M ais uma vez, seria útil ter indivíduos com personalidade não autoritária. A propósito, Fung (2003) defende a importância da social ização dos indivíduos para o bom funcionamento de uma democracia deliberativa, destacando o papel que associações horizontais podem ter no preenchimento dessa função. Fung (2003) e Cohen e Rogers (1995) não abordam a importância do processo de socialização das crianças em práticas e valores democráticos, mas certamente será mais fácil para as associações tornar civicamente virtuoso o cidadão se ele já tiver sido socializado desde a infância de uma forma democrática.

Na próxima seção, será abordado o desenvolvimento moral da criança e a importância do

2. A tradução desta e de todas as demais citações são de minha autoria. processo de socialização para o tipo de participação política do futuro cidadão. A ntes, entretanto, eu gostaria de fazer al guns comentários sobre duas maneiras de tratar esses temas que são, ao meu ver, infrutíferas, e uma terceira que me parece insuficiente.

Marsh (1971) critica o que considerava uma ênfase excessiva das pesquisas sobre socialização política no desenvolvimento de atitudes políticas em crianças. Ele faz basicamente duas críticas às pesquisas que revisou: (1) se tem procurado em crianças atitudes que só fazem sentido em adul tos, e (2) o pressuposto de relativa fixidez da personalidade é falso. A primeira crítica é pertinente: as atitudes políticas das crianças são um tanto quanto irrelevantes para suas atitudes políticas e comportamento político quando adultas. As crianças têm uma compreensão muito limitada, para dizer o mínimo, das questões políticas. Não faz muito sentido perguntar a crianças, por exemplo, o que el as acham do presidente da R epública. Q uanto à segunda crítica, $M$ arsh parece estar errado. Segundo H ofstede e M cCrae (2004, p. 57), pesquisas recentes sobre personalidade têm cada vez mais se baseado em traços de personalidade e usado um modelo que emergiu no início da década de 1990, o "modelo dos cinco fatores". As pesquisas têm consistentemente mostrado que os cinco fatores são variáveis adequadas para pesquisar a personalidade dos indivíduos de várias culturas e que esses cinco traços de personalidade são muito estáveis ao longo da vida adulta de um indivíduo (Hofstede e M cCrae, 2004, p. 57). ${ }^{3} 0$ mais importante, portanto, seria medir os traços de personal idade da criança que, no futuro, deverão ter impacto sobre seu comportamento político. E o que é realmente relevante é medir os aspectos da personalidade que dependem do processo de socialização, do processo de internalização dos valores e das práticas típicas de uma cultura, porque em relação a esses aspectos da personalidade seria possível pensar em mudanças na forma de educar as crianças que tivessem impacto sobre seu comportamento futuro como

3. Os cinco fatores, em inglês, são: neuroticism, extraversion, openness to experience, agreableness e conscientiousness (H ofstede e McCrae, 2004, p. 57). 
cidadão e, portanto, conseqüências para a democracia.

A segunda crítica dirige-se às idéias de M erelman (1980), que afirma não ser possível pensar numa contribuição da família para a democracia porque a estrutura interna da família é sempre distinta das instituições democráticas da sociedade tomada como um todo:

A família democrática ideal tem como objetivo ser uma produtora permanente de conexões emocionais. A polis democrática ideal tem como objetivo ser uma produtora de barganhas racionais temporárias. (M erelman, 1980, p. 468)

Como veremos na próxima seção, 0 ambiente emotivo terno no interior da família é fundamental para um saudável desenvolvimento moral da criança, e o desenvolvimento moral, por sua vez, é fundamental para a capacidade de participar de debates nos quais o objetivo é menos vencer do que chegar a um compromisso. Um adulto moralmente sofisticado tem boas chances de ser um bom cidadão para a democracia.

A terceira crítica novamente dirige-se a $M$ arsh. Ele sugere que sejam prioritariamente estudadas as elites políticas:

Tendo em mente o propósito das pesquisas sobre socialização política, parece-me que deveríamos estudar o comportamento (não as atitudes) da elite (não de toda a população) já que seu comportamento provavelmente é o mais influente na operação do sistema político. (M arsh, 1971, p. 464)

U m aspecto fundamental de uma sociedade democrática é o grau de participação política de sua população, das pessoas comuns. Um certo grau de apatia política pode ser sinal de que a sociedade não está passando por crises tão profundas que tentar interferir na política tenha passado a ser uma prioridade para a maioria da população, mas um certo grau - e de preferência um elevado grau - de participação política é um fator fundamental para 0 funcionamento democrático de uma sociedade. A ssim, não se pode desprezar a importância da social ização política da não-elite.
Feitos estes três comentários, passemos à discussão sobre socialização e desenvolvimento moral.

Desenvolvimento moral e processo de socialização

A o fazer suas pesquisas sobre como as crianças compreendiam e seguiam as regras dos jogos que praticavam, Piaget (1932) foi um pioneiro nos estudos empíricos sobre o desenvolvimento moral da criança. Diferentemente de Durkheim, que enfatizava a importância dos adultos para educar as crianças, transformandoas em adultos moralmente úteis para a sociedade, Piaget encontrou evidências de que a interação das crianças com seus colegas era mais importante para a formação de um cidadão capaz de compreender o ponto de vista do outro, de ter consciência e conseguir apresentar seus próprios argumentos e, enfim, de ser justo. 0 indivíduo moralmente sofisticado veria as normas como tendo sido feitas por indivíduos comuns como ele e, portanto, consideraria que elas poderiam ser modificadas a partir de um processo de discussão. Ele seria ainda capaz de distinguir entre 0 espírito e a letra da lei e, em certos momentos, poderia escolher não seguir a letra da norma para se manter fiel ao seu espírito, ou seja, em certos momentos, não se comportaria conforme o prescrito pelas normas para melhor corresponder às intenções subjacentes à norma, às intenções que ele imagina que estavam na mente dos que elaboraram as normas e com as quais ele concorda. 0 indivíduo moralmente sofisticado supera a fase do igual itarismo e aprende a agir com eqüidade. A o invés de considerar simplesmente que todos devem ser iguais perante a lei, ele sabe levar em consideração a situação de cada um no momento de aplicar as regras. As crianças maiores, por exemplo, tendem a dar alguma vantagem às crianças menores antes de começar um jogo para compensar seu menor desenvolvimento cognitivo e motor (Piaget, 1994).

Para Piaget, era em suas brincadeiras coletivas infantis que o indivíduo aprendia a ter um comportamento cooperativo e desenvolviase moralmente. A educação autoritária dos pais poderia bloquear o desenvolvimento moral da 
criança, na medida em que exigia obediência pela obediência, sem explicar à criança por que seria justo agir daquela forma. A lém disso, seria naturalmente mais fácil para uma criança aprender a se comportar com eqüidade com colegas da mesma idade - que, objetivamente, Ihe são muito semelhantes - do que com os adultos, muito mais velhos, mais experientes e interessados em assuntos de adultos. Piaget opunha, portanto, ao processo de socialização 0 processo de desenvolvimento moral.

Socialização e desenvolvimento moral, entretanto, são dois processos que ocorrem paral elamente eque podem ser distinguidos mais conceitual mente do que na prática. Social ização seria o processo de adequação da criança à sociedade por meio da internal ização de valores e comportamentos comuns em seu meio; seria a assimilação pelo indivíduo da cultura que está a sua volta. A o internalizar valores, o indivíduo segue as normas sociais não para evitar as punições que sofreria se não as seguisse, mas porque se sentirá melhor assim. Desenvolvimento moral seria o progresso que ocorreria na capacidade da criança de agir moral mente e de raciocinar acerca de questões morais de um modo que pode ser considerado sofisticado e conducente a um comportamento virtuoso e justo. 0 desenvolvimento moral seria a efetivação de um potencial biológico dos seres humanos para agir moralmente. Na prática, entretanto, como afirmam Gibbs e Schnell (1985), os dois processos estão intimamente inter-relacionados.

Walker, Henning e K rettenauer (2000) apóiam a tese de que um processo de socialização conduzido corretamente favorece 0 desenvolvimento moral. Eles fizeram uma pesquisa longitudinal durante quatro anos com sessenta crianças (trinta no final da infância e trinta no meio da adolescência). Cada criança participava de duas entrevistas: uma com um dos pais e outra com um amigo(a) do mesmo sexo que ela. $\mathrm{N}$ a entrevista, dois dilemas morais hi potéticos e um conflito real da vida da criança eram postos em discussão. A s discussões foram gravadas e codificadas e o nível de desenvolvimento moral das crianças foi medido no início e no final da pesquisa. Os autores encontraram correlações significativas entre o modo como se davam as discussões e o posterior progresso no desenvolvimento moral da criança. Tanto no caso das entrevistas com os pais, quanto nas entrevistas com os colegas, o envol vimento das crianças em discussões nas quais se tentava fazer uma representação própria do que se passava na mente do outro mostrou-se positivamente correlacionado com um mai or progresso no desenvolvimento moral da criança nos anos seguintes. Pelo contrário, não era favorável expor a criança a argumentos complexos e sobrecarregados de informação (o que podemos chamar de sermão):

Este achado [... ] indica que um estilo socrático e gentil de obter a opinião do outro e de verificar se houve compreensão [...] pode ser efetivo não apenas no contexto pais/filhos mas também entre colegas. A análise também revelou que nos dois contextos interações altamente informativas estavam associadas com baixas taxas de crescimento moral [...]. Embora interações informativas possam ser consideradas neutras, o fornecimento excessivo de informações pode ser percebido como uma aula carregada de opiniões. (Walker, H enning e K rettenauer, 2000, p. 1045)

Outro dado interessante foi o de que interações com alto grau de atos disruptivos da discussão (como distrações, desval orização do interlocutor, distorção do que foi dito pelo outro, ameaças e hostilidade) foram favoráveis ao desenvolvimento moral da criança no caso das discussões com os amigos, mas não nas discussões com os pais, o que pode ser entendido como uma corroboração das teses de Piaget:

0 achado [...] pode ser interpretado como consistente com a visão piagetiana de que relações i gualitárias entre amigos permitem uma expressão mais livre do conflito do que as relações assimétricas entre pais e filhos. (Walker, Henning e K rettenauer, 2000, p. 1045)

De acordo com os autores, Piaget errou ao considerar que os pais têm um papel mínimo no desenvolvimento moral da criança (Walker, Henning e K rettenauer, 2000, p. 1035). Piaget considerou mais importantes as relações igualitárias com os colegas do que as relações hierárquicas com os pais. Ele dizia, de certa forma, que os pais deveriam ser amigos da criança, ou 
seja, que quanto menos verticais fossem as relações entre pais e filhos melhor seria, e é justamente isso o que também aponta a pesquisa de Walker, Henning e K rettenauer (2000). Entretanto, Piaget, de fato, acreditava que mesmo pais bem intencionados não conseguiriam desempenhar o mesmo papel dos colegas da criança. Isto fica claro principalmente no terceiro capítulo do livro, do qual a seguinte citação é representativa:

É preciso notar, primeiramente, que, por mais que sejamos contrários a qual quer coação, mesmo moral, em educação, não é possível evitar, completamente, dar à criança ordens incompreensíveis para ela. (Piaget, 1994, p. 140)

O u seja, os pais têm, no mínimo, uma capacidade muito maior do que a criança e seus colegas de prever as conseqüências da ação da criança. Para que fazer uma coisa tão sem graça quanto estudar se brincar é muito mais divertido? Os pais (al guns) sabem a resposta.

Crianças de diferentes idades apresentam níveis distintos de desenvolvimento cognitivo e, portanto, não são igualmente susceptíveis às diferentes técnicas pedagógicas. As crianças menores ainda não estão preparadas para explicações abstratas. Elas ainda não têm um self bem desenvolvido, ou seja, não têm uma clara noção do que é apenas produto da sua mente e o que é fato exterior (Kochanska, 1994, p. 2021).

Entretanto, podemos extrair dos trabal hos de vários autores que, de uma maneira geral, os pais que mel hor conseguem internalizar val ores em seus filhos e, portanto, que podem ser considerados bem-sucedidos no processo de socialização da criança são aqueles que, ao se depararem com uma ação inadequada da criança, chamam-Ihe a atenção para o fato de que ela fez algo errado, explicam-Ihe as conseqüências do ato que acabara de cometer e deixam claro que ela é a responsável pelas más conseqüências desse ato. Para chamar a atenção da criança, os pais usam de vários recursos, que vão da chantagem emocional ao uso da força física e ao emprego de castigos diversos. Se os pais forem muito brandos nessa tarefa, a criança poderá não dar importância para o que eles estão falando; se forem excessivamente rigorosos, a criança ficará muito preocupada com a forma como está sendo castigada para dar a devida atenção às explicações das conseqüências de seus atos. A o explicar para a criança as conseqüências de seus atos, costumam ser mais efetivas as explicações que tornam a criança consciente de estar fazendo outra pessoa sofrer. Tais explicações seriam até mesmo mais eficazes do que outras que apelem para sentimentos egoístas da criança e informem-na que o que el a fez será prejudicial para ela própria. É próprio da criança a capacidade de sentir empatia. A ssim, de acordo com as teorias do desenvolvimento moral, a criança ficará mais sensibilizada se souber que sua mãe ficará triste se ela quebrar o vaso de flores do que se souber que será espancada caso quebre o vaso. No primeiro caso, será inevitável carregar o sentimento de cul pa; no segundo caso, bastará manter segredo sobre o fato de ter quebrado o vaso para o espancamento ser evitado. Também éútil ouvir as razões da criança no momento de lhe explicar as conseqüências de seus atos (Gibbs e Schnell, 1985; Grusec e Goodnow, 1994). Os pais autoritários, que exigem obediência estrita e sem discussão, não proporcionam à criança um ambiente favorável ao desenvolvimento da capacidade de raciocinar de modo sofisticado sobre questões morais:

Pais autoritários exigem obediência estrita e desencorajam a reciprocidade. Pais com autoridade também estabelecem controles firmes sobre o comportamento dos seus filhos, deles demandando um comportamento maduro, mas eles estão dispostos a ouvir o ponto de vista dos filhos e até mesmo a ajustar seu comportamento como resposta. Pais permissivos fazem poucas demandas e são pouco disciplinadores. São os pais com autoridade os mais bem-sucedidos na criação de filhos socialmente competentes e responsáveis, ou seja, que aceitam as ordens dos pais como suas próprias, sem sacrifício da curiosidade, originalidade e espontaneidade. (Grusec e Goodnow, 1994, p. 5-6).

Como resultado do processo de socialização e de características biológicas individuais, alguns adultos valorizam mais a autonomia individual e outros o conformismo às normas 
sociais, e isso tem implicações para o que, na literatura sobre social ização e política, é conhecido como personal idade autoritária. A preocupação com esse tema não é nova. Em 1950, A dorno, Frenkel-B runswik, L evinson eSanford publicaram um livro que teve grande repercussão, The authoritarian personality, no qual procuravam identificar em alguns indivíduos uma síndrome de características que os levaria a ser favoráveis a regimes ditatoriais e a apoiar a opressão de minorias (Martin, 2001). Desde então, diversos autores têm procurado descobrir quais fatores estariam correlacionados com 0 autoritarismo. Têm sido encontradas correlações, por exemplo, com culturas coletivistas, típicas de algumas culturas, e com certas religiões.

U m exemplo de diferença entre culturas coletivistas e individualistas é apresentado por M iller, Bersoff e Harwood (1990). Eles entrevistaram vários americanos e indianos de três faixas etárias (cerca de 7 anos, de 12 anos e de 21 anos), apresentando-Ihes alguns dilemas morais, e constataram que os indianos, mais do que os americanos, têm uma tendência a julgar a recusa de um indivíduo em ajudar outro em termos morais. Para os americanos, de cultura individualista, mais do que para os indianos, de cultura coletivista, era, por exemplo, legítimo um amigo se recusar a ajudar o outro se ele próprio já estivesse ocupado. N as sociedades individualistas, os indivíduos são vistos como portadores de um direito à liberdade de escol ha mais amplo do que nas sociedades coletivistas. K emmelmeyer et. al., em sua revisão de literatura, fazem, entre outras, as seguintes observações acerca das culturas coletivistas:

Pesquisas realizadas simultaneamente em várias culturas têm mostrado que membros de sociedades coletivistas são mais preocupados com a conformidade às normas sociais do que membros de sociedades individualistas. [...] O utras pesquisas sugerem que indivíduos com uma formação coletivista são mais propensos a basear suas decisões comportamentais nas normas do grupo e nas expectativas dos outros do que na sua própria preferência [...]. Além disso, há evidências de que pessoas de sociedades coletivistas, mais do que aquelas de sociedades individual istas, têm um sentimento de obrigação para com membros do seu grupo, mostram-se deferentes para com as autoridades do seu grupo, vêm distinções claras entre os membros do seu próprio grupo e os membros dos outros grupos, e apresentam atitudes mais favoráveis a membros do próprio grupo. (Kemmelmeyer et al., 2003, p. 306)

Embora algumas pesquisas indiquem se tratar de um fenômeno que se manifesta mais intensamente nas culturas coletivistas, parece ser universal a tendência a ter idéias preconceituosas em relação às pessoas que não pertencem ao próprio grupo. N esdale e F essler (2001) citam Tajfel eTurner como um clássico no tema da interação entre grupos por terem desenvolvido, em 1979, uma teoria da identidade social que tem sido desde então sucessivamente corroborada por estudos empíricos. ${ }^{4}$ D e acordo com essa teoria, os membros dos grupos de baixo status usam de várias estratégias para tentar mudar seu status: (a) tentam deixar o próprio grupo e ingressar no grupo de status el evado; (b) enfatizam as características em que seu próprio grupo é superior; (c) invertem a escala de val ores para se sentir num grupo de status mais elevado, e (d) se comparam com grupos de status ainda mais baixo (N esdale eF essler, 2001, p. 508). Nesdale e Fessler fizeram um experimento com crianças, em que el as foram divididas em um grupo de al to status (excelentes desenhistas) e um grupo de baixo status (boas desenhistas). As crianças reagiram conforme 0 previsto pela teoria da identidade social em todos os aspectos, com exceção da tentativa de adotar estratégias para mudar o status do próprio grupo. Os autores, entretanto, acham provável que a pesquisa tal como foi feita não tenha sido capaz de captar esse comportamento que, em outras condições, talvez também se manifestasse entre as crianças ( N esdale e Fessler, 2001, p. 514).

O utra pesquisa cujos resultados corroboram a tese de que crianças são capazes de se sentir pertencentes a um grupo foi realizada por B igler, B rown e $M$ arkell (2001). Eles fizeram um experimento com crianças com idade entre 7 e 12 anos inscritas numa escola durante a temporada de férias e divididas em classes conforme o nível

4. $O$ texto indicado por Nesdale e Fessler é: Tajfel, H., \& Turner, J. An integrative theory of intergroup conflict. In: A ustin, W. G. \& Worchel, S. (Eds.). The social psychology of intergroup relations. M oeterey, CA: Brooks/Cole, 1979. 
intel ectual. A s crianças receberam blusas amarelas ou azuis e havia três tipos de sala de aula: (1) cartazes mostravam pessoas com camisas amarelas sendo mais bem-sucedidas do que pessoas com camisas azuis e a professora diferenciava os alunos entre azuis e amarelos, embora não favorecesse nenhum dos dois grupos; (2) os cartazes estavam presentes, mas a professora não diferenciava os al unos pela cor da blusa; 3) salas dos grupos de controle, onde os alunos vestiam blusas amarel as e azuis, mas não havia nem cartazes nem os alunos eram diferenciados pela professora em função da cor da blusa. Foram medidas a auto-estima e a habilidade classificatória dos alunos antes e depois da experiência (que durou quatro semanas). D epois do experimento, foram novamente medidas a auto-estima e a habilidade classificatória e, ainda, como as crianças avaliavam o próprio grupo e o outro grupo e com quais colegas prefeririam brincar. $N$ ão houve evidências de que a escolha dos colegas para brincar fosse influenciada pela cor de sua blusa. 0 fator mais importante era o gênero do colega. D e uma maneira geral, os cartazes apenas não foram suficientes para induzir nas crianças preconceitos em relação aos grupos. M as o preconceito se desenvolveu quando, além dos cartazes, na sala de aula havia também uma classificação das crianças feitas pela própria professora. Bigler, Brown e M arkell supõem que, na vida real, a importância da existência de grupos perceptivelmente diferentes seja mais importante do que no experimento, por três motivos:

$M$ ensagens de status referentes a grupos sociais reais (por exemplo, minorias étnicas e raciais) diferem das usadas aqui porque elas tipicamente (1) estão presentes em múltiplos ambientes (e não apenas na escola), (2) são al tamente salientes porque envolvem modelos (e não cartazes), e (3) e se apresentam por um longo período de tempo (e não apenas por umas poucas semanas). (1999, p. 1160)

Eu acrescentaria que os pais das crianças são mais importantes para elas do que seus professores e que, portanto, se forem eles os adultos que fazem a diferenciação, será ainda mais marcante na criança a existência de grupos. Os dois experimentos relatados acima indicam que mesmo crianças pequenas já fazem distinções e elaboram preconceitos em relação a membros de outros grupos. De acordo com Bigler, Brown e M arkell, al gumas pesquisas "sugerem que crianças com apenas 3 anos de idade já estão atentas para comparações de grupos" (1999, p. 1152).

Outra variável comumente correlacionada com personalidade autoritária éfiliação religiosa. Tibon e B lumberg (1999), por exemplo, mostram que, quanto mais religiosos, menos os jovens universitários judeus de Israel tendem a apoiar o processo de paz no Oriente M édio. Os autores atribuem isso ao fato de jovens religiosos terem sido submetidos a um processo de socialização que envolve códigos de conduta rígidos (Tibon e Blumberg, 1999, p. 583). M as por que esse tipo de social ização tenderia a produzir uma personalidade autoritária? Encontramos um ensaio de resposta para essa pergunta em $\mathrm{N}$ arvaez et. ali (1999). Para esses autores, o responsável pelo autoritarismo é o fundamental ismo religioso e não propriamente a filiação a esta ou àquela religião (Narvaez et al., 1999, p. 485). Esses autores aplicaram um questionário que incluía al guns testes psicológicos e atitudinais a membros de duas igrejas cristãs dos EUA, a A merican $B$ aptist Congregation e a U nited Church of Christ, a primeira conhecida por ser conservadora e a segunda por ser liberal. E m seguida, eles aplicaram o mesmo questionário a estudantes universitários. Entre os entrevistados, 0 fundamentalismo era maior entre aqueles que tinham pontuação média no teste de nível de desenvolvimento moral. ${ }^{5}$ Os autores forneceram a seguinte explicação para seus achados empíricos:

A formação do pensamento moral ortodoxo é especial mente provável de ocorrer à medida que o processo de jul gamento moral está desenvolvendo 0 esquema de manutenção de normas [...]. Então, a pessoa reconhece a necessidade de normas sociais para estabel ecer e estabilizar a ordem, sendo especialmente levada ao fundamentalismo religioso, que fornece normas claras

\footnotetext{
5. No teste de desenvolvimento moral, desenvolvido por $\mathrm{K}$ ohlberg, atingem pontuação mais el evada os indivíduos que demonstram ter superado o nível convencional de raciocínio acerca de questões morais, ou seja, que, na terminologia de Piaget (1994), são capazes de pensar em termos de eqüidade e não simplesmente em termos igualitários.
} 
e autoridades fortes. Portanto, o julgamento moral pode fornecer a concreticidade conceitual (os conceitos epistemológicos) para uma ideologia. Simultaneamente, se a pessoa está reiteradamente exposta ao fundamentalismo religioso, a força das autoridades religiosas se transfere para as autoridades civis [...]. E mais, se o fundamentalismo religioso vê o questionamento de sua autoridade como al go para além do entendimento humano, proibido de se questionar e debater, então a pessoa tem bloqueado seu progresso ao pensamento pósconvencional, o qual se baseia no escrutínio aberto e no debate. (N arvaez et al., 1999, p. 487).

0 mecanismo explicitado por $\mathrm{N}$ arvaez et al. permite pensar em como um determinado tipo de processo de socialização, próprio de culturas fundamentalistas e autoritárias, pode bloquear o desenvolvimento moral do indivíduo, deixando-o menos propenso à discussão aberta e, portanto, menos apto à vida numa sociedade democrática.

N os últimos parágrafos, estivemos acompanhando os trabalhos de alguns pesquisadores que, num certo sentido, seguem o rumo traçado por A dorno e seus colaboradores em 1950 e procuram identificar os indivíduos mais propensos a desenvolver uma personali dade autoritária. $M$ artin (2001), entretanto, aponta vários defeitos metodológicos e de interpretação dos dados cometidos por Adorno et al. em The authoritarian personality. De acordo com Martin, erros equival entes, embora menos sérios, também se encontram presentes em obras contemporâneas. 0 argumento básico de $M$ artin é que existe um continuum entre autoritários e nãoautoritários, não sendo os autoritários puramente autoritários, possuidores de todas as características que possam ser atribuídas a um tipo ideal de indivíduo autoritário. 0 raciocínio inverso também é válido. Os não-autoritários também apresentam características que podem ser consideradas típicas dos autoritários.

Feldman (2003) chega a conclusão semeIhante, de que autoritários e não-autoritários não têm personalidades radicalmente diferentes. ${ }^{6}$

\footnotetext{
$\overline{6 . ~ F e l d m a n ~(2003, ~ p . ~ 67), ~ e n t r e t a n t o, ~ c o n s i d e r a ~ q u e ~ s u a ~}$ teoria está mais próxima da obra de A dorno et al. do que da teoria de Altemeyer, um autor citado em vários dos artigos como o mais importante estudioso contemporâneo do tema.
}

Feldman, entretanto, vai além. Ele propõe uma nova teoria que nos permite explicar por que a tese de $\mathrm{M}$ artin estaria correta. De acordo com Feldman (2003), o preconceito e a intolerância, típicos do indivíduo com personalidade autoritária, podem ser encontrados tanto em pessoas que mais valorizam a autonomia individual, quanto entre os que valorizam o conformismo. 0 preconceito e a intolerância encontram-se associados a um sentimento de insegurança, que se apresenta nos indivíduos quando eles sentem que a ordem social encontra-se ameaçada. A desordem social tem conseqüências indesejáveis tanto para individual istas quanto para conformistas, como um aumento na possibilidade de ser vítima de atos violentos. Como lembra Feldman, é de se esperar que os individualistas não sintam uma aversão menor à idéia de viver em uma sociedade violenta do que os conformistas (Feldman, 2003, p. 50). A queles com personalidade conformista, entretanto, teriam uma maior tendência a se comportar de modo autoritário porque têm maior facilidade de interpretar o que ocorre à sua volta como ameaças à ordem social. De acordo com Feldman, 0 motivo dessa maior insegurança não é perfeitamente conhecido, mas, possivel mente, se trata de uma visão diferenciada da natureza humana. O s indivíduos que val orizam mais a autonomia pessoal tenderiam a acreditar ser possível haver ordem social com base na interação entre indivíduos autônomos. Os conformistas, por sua vez, teriam uma visão mais pessimista:

Não é necessário acreditar que as pessoas são inerentemente anti-sociais; basta crer que não será produzida uma ordem social estável se as pessoas forem deixadas aos seus próprios desígnios, perseguindo seus interesses próprios e se comportando livremente. (Feldman, 2003, p. 48)

Feldman (2003, p. 54) elaborou um questionário em que procurava medir os níveis de conformidade, medo de desordem, respeito às normas, percepção da existência de coesão social e valores relativos à educação das crianças, e encontrou resultados que corroboraram sua teoria: "[... ] para baixos níveis de ameaça social não há ef eito significativo da conformidade social-autonomia sobre o preconceito" (Feld- 
man, 2003, p. 62). Feldman chama a atenção para 0 fato de sua teoria e seus resultados empíricos contrariarem outras que atribuem ao indivíduo autoritário um complexo de características que o tornam inerentemente autoritário.

Feldman não informa se encontrou a correlação esperada entre ser socialmente conformista e valorizar uma educação conformista das crianças, mas outros estudos, como podemos ver a seguir, encontraram evidências de que há transmissão intergeracional de valores e atitudes. U $m$ desses estudos é o de Beck e Jennings (1975), que compararam a preferência partidária de estudantes nos EUA com a preferência partidária de seus pais e avós. Os dados mostraram que, quando o casal não tinha originariamente a mesma preferência partidária, era mais freqüente a esposa mudar de preferência partidária do que o marido. M ostraram também que a preferência partidária dos filhos é mais freqüentemente igual à da mãe do que à do pai. A inda assim, os filhos têm preferência partidária mais parecida com a dos avós paternos do que com a dos avós maternos porque é mais freqüente a mulher se adequar à preferência partidária do marido do que o inverso.

A discussão sobre transmissão de preferência partidária é um tanto quanto irrelevante para grande parte dos países do mundo, inclusive para o caso brasileiro. Ela é válida para os EUA porque lá democratas e republicanos al ternamse no poder há décadas. L evando isso em consideração, Westholm e N iemi (1992) fizeram uma pesquisa sobre transmissão intergeracional de atitudes envolvendo um número maior de países (Finlândia, Suécia, Itália, H olanda, Á ustria, Grã-B retanha, A lemanha Ocidental e Estados Unidos) e avaliaram não só a reprodução da preferência partidária, mas também do posicionamento ideológico. Eles constataram que, para os países com um sistema partidário relativamente estável, a transmissão de preferência partidária é maior do que a transmissão de outras atitudes. Os autores argumentam que isso ocorre porque os partidos representam al go mais concreto do que noções abstratas, cujo domínio énecessário para se posicionar ideologicamente. Ou seja, é de se esperar uma menor transmissão intergeracional de preferências ou atitudes em relação a questões mais abstratas:
Partidos são concretos. A ntes que possam compreender muito mais da vida política, crianças pequenas podem compreender a noção de que na política, como em outras áreas, há grupos e times lutando uns com os outros e de que de alguns se deve gostar mais do que de outros. Partidos são visíveis. $\mathrm{Na}$ maioria dos países, el es dominam o noticiário e os discursos políticos tanto durante, quanto entre as eleições. Porque os partidos são concretos e visíveis, os sentimentos partidários são facilmente comunicáveis. A s chances de que as preferências partidárias apareçam em conversações familiares e que sejam corretamente compreendidas pela criança são provavelmente maiores do que as de outras atitudes políticas. (Westholm e Niemi, 1992, p. 30)

Em outra pesquisa, Westholm (1999), com base em um survey realizado na Suécia, mostra que as opiniões políticas dos adolescentes são influenciadas pela opinião política dos pais. Tratou-se de uma pesquisa de painel, tendo sido possível encontrar evidências de que a visão política dos adolescentes, à medida queel es crescem, torna-se mais parecida com as dos pais. A discussão sobre transmissão intergeracional de preferência partidária e de posicionamento ideológico é indicativa do que deve acontecer com outros valores importantes para a vida política de um país. A s pesquisas mencionadas acima são forte indicativo de que o processo de socialização por que passam as crianças é algo importante para sua futura partici pação política.

U m dos fatores necessários a uma participação política de qualidade é o conhecimento da realidade política. Nesse aspecto, os indivíduos de personal idade autoritária saíram-se pior do que os de personalidade não autoritária no estudo de Peterson, D uncan e Pang (2002). Eles aplicaram um questionário contendo, de um lado, questões que mediam o nível de autoritarismo e posicionamento ideológico do indivíduo entre direita e esquerda e, de outro lado, al gumas questões que avaliavam o grau de informação dos respondentes em relação a questões políticas. ${ }^{7}$

\footnotetext{
7. Para medir 0 autoritarismo e o posicionamento ideológi$\mathrm{CO}$, os autores utilizaram o Right-Wing A uthoritarianism Scale, desenvolvido por A ltemeyer, que é justamente o principal autor criticado por Feldman (embora Feldman também 0 elogie muito). Feldman adverte que a escala, como 0 próprio nome reconhece, só mede autoritarismo de direita (Feldman, 2003, p. 44).
} 
Os autores encontram uma correlação negativa entre as pessoas que têm um perfil autoritário e conhecimento político. Já M uhlberger (2000) aplicou um questionário a 119 alunos de graduação em que media o nível de sofisticação moral, o nível de responsabilidade ética e a habilidade cognitiva dos respondentes. Em seguida, os respondentes que demonstraram interesse em participar de grupos de discussão receberam um telefonema convidando-os para uma reunião de um grupo semelhante ao que eles haviam demonstrado ter interesse. Ter um nível de desenvolvimento moral elevado não foi determinante para o indivíduo comparecer ou não às reuniões. Entretanto, houve diferença de motivação entre aqueles com nível moral elevado (pós-convencional) e aqueles com nível moral em estágio convencional:

A únicas influências diretas ou indiretas significativas sobre a motivação dos altamente não-sofisticados são as expectativas de satisfação psicológica (internal rewards) e incentivos seletivos. Em contraste, [...] os sofisticados baseiam suas decisões no senso de responsabilidade em contribuir para os objetivos do grupo, na percepção do valor moral dos objetivos do grupo, e, em menor grau, na percepção da relevância para si próprio do objetivos. (M uhl berger, 2000, p. 689)

Diferentes culturas, diferentes processos de socialização

Como já mencionado nas seções anteriores, freqüentemente encontra-se na literatura sobre socialização e política uma oposição entre dois tipos de cultura - individualista e col etivista -, sendo as culturas individual istas vistas como mais apropriadas para a democracia. 0 predomínio de uma cultura individualista é maior nas sociedades com democracia consolidada há mais tempo do que nas democracias recentes ou nos regimes autoritários. Como indicam Kemmelmeyer et al. (2003, p. 306) em sua revisão de literatura, os indivíduos de culturas coletivistas seriam mais influenciáveis pela vontade da maioria e estariam mais dispostos a abdicar das próprias preferências e a se comportar de acordo com as expectativas de outras pessoas, principalmente as do seu próprio grupo.
Recentemente, essa abordagem tem sido estendida ao conceito de capital social. A llik e Realo (2004) compararam os índices de individualismo e de capital social de 42 países e descobriram que a correlação entre os dois índices é positiva e estatisticamente significativa: os países mais individual istas têm capital social mais el evado. ${ }^{8}$

Essa visão de ser a cultura individualista a única adequada para a democracia tem sido contestada por al guns autores. Como vimos, de acordo com a teoria de Feldman, autoritarismo não pode ser considerado sinônimo de coletivismo (ou do conceito de conformismo social utilizado por ele). Num posicionamento que podemos considerar congruente com o de Feldman, Stepan (2000), ao discutir a relação entre religião e democracia, argumenta que não existem religiões antidemocráticas. De acordo com Stepan, sequer é necessário uma separação absoluta entre Estado e religião para a constituição de uma sociedade democrática. 0 importante é que, além de serem preenchidos os requisitos formais comumente mencionados por cientistas políticos, exista uma dupla tolerância: que 0 Estado tolere a existência da religião e que a religião tolere a existência do Estado ou, mais precisamente, que os indivíduos para os quais nada é mais importante do que sua religião aceitem a existência da democracia e os indivíduos preocupados com o estabelecimento e manutenção da democracia não vejam que, para isso, seja necessário suprimir as práticas religiosas.

Em apoio à sua tese, Stepan apresenta evidências de que religiões como islamismo, confucionismo e católica ortodoxa não são impedimentos para a democracia. No interior de cada uma delas, assim como nas diversas versões do cristianismo no 0 cidente, podem tanto ser encontrados argumentos favoráveis

8. 0 B rasil, simultaneamente, é, entre 42 países, o que apresenta menor índice de confiança interpessoal e, entre 23 países, aquele cujos indivíduos são os mais solícitos em ajudar um estranho na rua. A primeira informação pode ser encontrada em Allik e Realo (2004, p. 38); a segunda é resultado da pesquisa de Levine, Norezayan e Philbrick (2001, p. 551). Como comentou o professor Bruno Reis (UFMG) em sala de aula, mais do que simples curiosidade, certamente essa surpreendente incongruência aponta para problemas metodológicos na produção dos dados. 
como contrários à democracia. Há países cuja maioria da população é filiada a cada uma das três religiões citadas acima e que atualmente são, já foram, ou têm intermitentemente sido democráticos. Quando o contexto internacional e as condições étnicas, econômicas, militares e sociopolíticas em geral são favoráveis, um país de qual quer uma dessas religiões pode assumir uma configuração democrática, com o aparecimento de líderes que encontram na própria religião argumentos em defesa da democracia (Stepan, 2000).

0 refinamento teórico dos conceitos de individual ismo e de coletivismo e os achados empíricos de K emmelmeyer et al. corroboram, simultaneamente, as afirmações de Stepan (2000) e de Feldman (2003). K emmelmeyer et al. aplicaram questionários a indivíduos de sete países (A lemanha, Bulgária, Canadá, EUA, Japão, N ova Zelândia e Polônia) para medir o nível de autoritarismo e os níveis horizontais e verticais de individualismo e de coletivismo. A s distinções conceituais entre os diferentes tipos de coletivismo e individualismo foram as seguintes:

[... ] o conceito psicológico de individualismo vertical (IV) val oriza a competição e a superação dos outros; 0 individualismo horizontal $(\mathrm{IH})$ caracteriza o desejo de ser único, diferente dos semel hantes; o coletivismo vertical (CV) inclui a valorização da tradição e 0 respeito pela família; por fim, o coletivismo horizontal $(\mathrm{CH})$ é formado por um senso de interdependência e conexão com membros do próprio grupo. (Kemmelmeyer et al., 2003, p. 312)

Os autores não encontraram correlação entre a pontuação obtida pelos respondentes no teste para medir autoritarismo de direita e a medida de coletivismo horizontal (2003, p. 314). Por outro lado, 0 autoritarismo estava positivamente relacionado às modalidades verticais tanto do individualismo, quanto do coletivismo, mas não às modalidades horizontais:

[... ] tanto no nível individual, quanto no nível social, o Estudo 2 [o questionário foi aplicado a dois grupos de entrevistados] demonstrou que 0 autoritarismo está associado somente com esses aspectos do coletivismo que se referem à hi erarquia e à submi ssão à autoridade do grupo. O utros aspectos do coletivismo, ou seja, a ênfase na proximidade e nas conexões interpessoais com membros do próprio grupo não estão correl acionados com o autoritarismo. I sso confirma nossa hipótese de uma sobreposição conceitual na definição de autoritarismo ecoletivismo. (K emmelmeyer etal., 2003, p. 316317)

É interessante observar que as teorias de Feldman (2003) e deK emmelmeyer et al. (2003) corroboram-se mutuamente, apesar de nenhum dos autores citar o trabalho do outro. Eles chegaram de forma independente - e embasados tanto em considerações teóricas quanto em achados empíricos - a fazer praticamente a mesma crítica ao trabalho de Altemeyer: a escala de autoritarismo de direita confunde duas coisas distintas, autoritarismo e coletivismo ou conformismo social. Um indivíduo pode identificar-se com políticas de esquerda e ser autoritário; outro pode apresentar elevado grau de conformismo social e não ser autoritário.

\section{Conclusões}

Os trabalhos revisados não respondem diretamente à pergunta se o processo de socialização pelo qual passa o indivíduo durante sua infância tem impacto sobre a quantidade e a qualidade da sua participação política quando adul to. Eles, entretanto, mostram evidências de que o processo de socialização tem impacto sobre a formação da personalidade do indivíduo, incluindo o nível de sofisticação de seu raciocínio em questões morais, e sobre suas atitudes diante de questões políticas. Com uma certa dose de especulação, é possível extrair das evidências apresentadas algumas conclusões de caráter provisório.

A família democrática, ou seja, a família que tenderia a produzir futuros bons cidadãos para a vida numa sociedade democrática, seria não exatamente uma família que colocasse em votação qual será o cardápio do jantar, mas uma em que os pais evitassem impor regras de comportamento e noções de certo e de errado sem sequer ouvir o que a criança teria a dizer sobre 0 assunto. Os pais nessa família procurariam constantemente el evar a capacidade de seus filhos de compreenderem os benefícios, 
para a criança e para as outras pessoas, decorrentes de seguir as normas sociais. Os valores transmitidos poderiam tanto ser mais voltados para o respeito à liberdade do outro (valores individualistas, mas não egocêntricos), como para a importância de não escandalizar as outras pessoas com um comportamento estranho (valores col etivistas, mas não vistos como al go de origem supra-humana).

A participação política do indivíduo depende de inúmeros fatores e não somente, e talvez nem mesmo de forma particularmente significativa, de seu nível de desenvolvimento moral. M as, de um país povoado por cidadãos capazes de raciocínios sofisticados em questões morais, é de se esperar uma participação de qualidade. O u seja, é de se esperar que os indivíduos sejam capazes de participar de discussões e de chegar a compromissos que reduzam os conflitos e aumentem o nível de eqüidade da sociedade.

A bstract: After a brief characterization of democratic societies, the paper presents a revision of literature on moral development and socialization. Then, the impact of dif ferent allture on democracy is disoussed and, finally, some considerations on the relevance of the socialization process for democracy are made.

K ey-words: democracy, political participation, socialization, moral development.

\section{Referências}

A LLIK , Jüri; REA L O, A nu. Individualism-collectivism and social capital. J ournal of Cross-Cultural Psychology. v. 35, n. 1, janeiro, 2004. p. 29-49.

A V RITZER, Leonardo. Teoria democrática e deliberação pública. Lua N ova, n. 49, 2000. p. 25-46.

BECK, Paul A llen; J E N N IN GS, M. K ent. Parent as "middlepersons" in political socialization. The J ournal of Politics, v. 37, n. 1, fevereiro, 1975. p. 83107.

BIGLER, RebeccaS.; BROW N, Christia; M ARKELL, $M$ arc. When groups are not created equal: effects of group status on the formation of intergroup attitudes in children. Child D evelopment, v. 72, n. 4, julho/agosto, 2001. p. 1151-1162.

COHEN, J oshua; ROGERS, J oel. Secondary associations and democratic governance. In: (Eds.).
Associations and democracy. Londres: Verso, 1995. p. 7-98. [Série The Real U topia Project, v. 1].

FELDM A N, Stanley. Enforcing social conformity: a theory of authoritarianism. Political Psychology, $v$. 24, n. 1, 2003. p. 41-74.

FUNG, A rchon. A ssociation and democracy: between theories, hopes, and realities. Annual Review of Sociology, v. 29, agosto, 2003. p. 515-539. GIBBS, J ohn C.; SCHNELL, Steven V. M oral development "versus" socialization: a critique. American Psychologist, v. 40, n. 10, outubro, 1985. p. 1071-1080.

GRUSEC, J oan E.; GOODNOW , J acqueline J I Impact of parental discipline methods on the child's internalization of values: a reconceptualization of current points of view. D evelopmental P sychology, v. 30, n. 1, 1994. p. 4-19.

HOFSTEDE, Geert; M CCRA E, RobertR. Personality and culture revisited: linking traits and dimensions of culture. Cross-Cultural Research, v. 38, n. 1, fev., 2004. p. 52-88.

KELSEN, Hans. Essência evalor da democracia. In: A democracia. São Paulo: M artins Fontes, 1993. p. 23-107.

KEM M EL MEYER, M arkus; et al. Individualism, collectivism, and authoritarianism in seven societies. J ournal of Cross-Cultural Psychology, v. 34, n. 3, maio, 2003. p. 304-322.

K OCHA NSKA, Grazyna. B eyond cognition: expanding the search for the early roots of internalization and conscience. D evelopmental Psychology, v. 30, n. 1, 1994. p. 20-22.

LEVINE, Robert V.; NORENZAYAN, A ra; PHIL $B R I C K, K$ aren. Cross-cultural differences in hel ping strangers. J ournal of Cross-Cultural Psychology, v. 32, n. 5, Set, 2001. p. 543-560.

M A RSH, David. Political socialization: the implicit assumptions questioned. British J ournal of Political Science, v. 1, 1971. p. 453-465.

M A RTIN, J ohn L evi. The authoritarian personality, 50 years later: what lessons are there for political psychology? Political Psychology, v. 22, n. 1, 2001. p. 1-26.

MERELM AN, Richard M. The family and political socialization: toward a theory of exchange. The J ournal of Politics, v. 42, 1980. p. 461-486.

MILLER, J oan G.; BERSOFF, David M .; HARW OOD, Robin L. Perceptions of social responsibilities in India and in the U nited States: moral imperatives or personal decisions? Journal of Personality and Social Psychology, v. 58, n. 1, 1990. p. 33-47. 
M UHLBERGER, Peter. M oral reasoning effects on political participation. Political Psychology, v. 21, n. 4, 2000. p. 667-695.

NA RVA EZ, D arcia; GETZ, Irene; REST, J ames R .; THOM A , Stephen J. Individual moral judgment and cultural ideologies. Developmental Psychology, v. 35 , n. 2, 1999. p. 478-488.

NESDA LE, D rew; FLESSER, Debbie. Social identity and the development of children's group attitudes. Child D evelopment, v. 72, n. 2, março/abril, 2001. p. 506-517.

PETERSON, Bill E.; DUNCAN, Lauren E.; PANG, Joyce $S$. A uthoritarianism and political impoverishment: deficits in knowledge and civic disinterest. Political Psychology, v. 23, n. 1, 2002. p. 97-112.

PIA GET, J ean. 0 juízo moral na criança. 3. ed. São Paulo: Summus, 1994.

PUTNAM, Robert. Comunidade e democracia: a experiência da Itália moderna. Rio de J aneiro: Editora Fundação G etúlio Vargas, 1996.

ROUSSEA U, J ean-J acques. D o contrato social. São Paulo: Editora A bril Cultural, 1987. [Coleção Os Pensadores].
SCHU M PETER, J oseph. Capitalismo, socialismo e democracia. Rio de J aneiro: Fundo de Cultura, 1961. STEPA N, A Ifred. Religion, democracy and the 'twin tolerations'. J ournal of Democracy, v. 11, n. 4, outubro, 2000. p. 37-57.

TIB ON, Shira; BLU M BER G, Herbert H. A uthoritarian and political socialization in the context of the A rab-I sraeli conflict. Political Psychology, v. 2, n. 3, 1999. p. 581-591.

WALKER, Lawrence J., HENNING, Karl H., e KRETTENA UER, Tobias. Parent and peer contexts for children's moral reasoning development. Child Development, v. 71, n. 4, julho/agosto, 2000. p. 10331048.

WESTHOL M , A nders; NIEM I, Richard G. Political institutions and political socialization. Comparative Politics, outubro, 1992. p. 25-41.

WESTHOLM, Anders. The perceptual pathway: tracing the mechanisms of political value transfer across generations. Political Psychology, v. 20, n. 3, 1999. p. 525-551. 